\title{
Análise histórico-espacial do setor hoteleiro no núcleo urbano central de Florianópolis-SC ${ }^{*}$
}

\author{
Fabíola Martins dos Santos** \\ Raquel Maria Fontes do Amaral Pereira ${ }^{* * *}$
}

\section{Resumo}

Este texto trata da expansão urbana e do crescimento das atividades turísticas de Florianópolis, buscando apreender suas relações com o desenvolvimento do setor hoteleiro, localizado em seu núcleo central, desde as iniciativas pioneiras até os dias de hoje. Partindo do entendimento de que o espaço urbano é produto de relações sociais historicamente determinadas, foi definida, como área objeto do estudo, uma porção do espaço urbano insular da capital de Santa Catarina, correspondente ao seu centro histórico, cuja organização espacial passa por um acelerado processo de transformação, abrigando atualmente 24 hotéis. O desenvolvimento da pesquisa impôs a definição de um referencial teórico apropriado ao entendimento da expansão urbana e turística, de modo a favorecer a apreensão da totalidade dos elementos naturais e humanos definidores da realidade investigada, tendo por base categorias analíticas propostas por Milton Santos.

Palavras-chave: Formação sócio-espacial; Desenvolvimento urbano e turístico; Rede hoteleira.

* Este trabalho é parte da Dissertação de Mestrado defendida em 2005 no Curso de Pós-Graduação Stricto Sensu em Turismo e Hotelaria da Universidade do Vale do Itajaí (UNIVALI).

** Professora do Centro de Educação Tecnológica de Santa Catarina CEFET (fabiola@cefetsc.edu.br).

*** Professora do Programa de Mestrado e Turismo e Hotelaria da UNIVALI (raquelfontes@brturbo.com.br).

Geosul, Florianópolis, v. 23, n. 46, p 115-135, jul./dez. 2008 
SANTOS, F.M dos \& PEREIRA, R.M.F.A. Análise histórico-espacial do ...

Historic and spatial analysis of the hotel sector in the urban area of Florianópolis-SC

\begin{abstract}
This text presents some reflections concerning the urban and tourist expansion of the city of Florianópolis, trying to identify its implications on the development of the hotel sector located in its central area, departing from the pioneer initiatives until the present days. The work departs from the understanding that space organization results from historically determined social relations. The study area includes part of the urban space of the island of Santa Catarina, corresponding to its historic center, whose spatial organization is going through an accelerated transformation process, hosting 24 hotels. The accomplishment of the research required the definition of theoretical references adequate to the understanding of the expansion process of the city and of the tourist flows, so that the totality of the natural elements and human definers of the investigated reality could be perceived, considering the analytic categories proposed by Milton Santos.

Key words: Socio-spatial formation; Urban and Tourist Development; Hotel Sector.
\end{abstract}

\title{
Introdução
}

O presente trabalho procura analisar as transformações geradas na área correspondente ao núcleo central de Florianópolis, decorrentes da expansão urbana e do crescimento da atividade turística e os seus reflexos sobre o desenvolvimento da rede hoteleira local.

A área objeto do estudo corresponde a uma porção do espaço urbano da capital do estado de Santa Catarina, onde a organização espacial, fruto de diferentes períodos históricos, tem sofrido um processo contínuo de transformação imposto pelo crescimento da própria cidade. Assim sendo, a investigação parte do entendimento de que a organização do espaço é fruto da combinação de elementos naturais e humanos e de relações sociais 
SANTOS, F.M dos \& PEREIRA, R.M.F.A. Análise histórico-espacial do ...

historicamente determinadas, pois o processo de produção que é, ao mesmo tempo, histórico e social imprime suas marcas sobre a materialidade.

A pesquisa trata da evolução do setor hoteleiro localizado na área central, relacionando-o à expansão urbana da cidade, à mudança funcional do seu centro histórico nos 30 anos e aos fluxos turísticos. A área de estudo compreende o espaço insular situado a oeste do Morro da Cruz, de forma triangular, delimitado pelas baías Norte e Sul e pela Avenida Mauro Ramos que tem, em um dos seus vértices, a Ponte Hercílio Luz, abrigando atualmente 24 hotéis.

O referencial teórico utilizado tem por base categorias analíticas que permitem compreender a gênese e a evolução do núcleo urbano de Florianópolis, inserido no contexto regional, nacional e internacional em diferentes períodos históricos e, ao mesmo tempo, interpretar o desenvolvimento do setor hoteleiro diante da expansão urbana e do crescimento dos fluxos turísticos locais, sem, entretanto, analisar os hotéis localizados na periferia do centro e nos balneários. Os marcos teóricos que sustentam a pesquisa apóiam-se nas contribuições de autores dedicados à análise da realidade sócio-espacial, nela incluída o fenômeno turístico. Na base da reflexão está o paradigma de formação sócioespacial proposto por Milton Santos que favorece a realização de estudos de caráter globalizante, por considerar as "múltiplas determinações", responsáveis por uma realidade concreta cujas especificidades têm explicações de ordem natural e humana. Ao considerar as características físicas do espaço onde a cidade surgiu e as relações sociais dominantes nos diferentes períodos da sua história, o paradigma de formação sócio-espacial propicia um enfoque multidisciplinar no qual o espaço geográfico e o tempo histórico despontam como aspectos essenciais para a apreensão de uma realidade em que as características naturais vão sendo modificadas para responder às exigências sociais, definidas por imposições locais, regionais, nacionais e/ou internacionais. 
SANTOS, F.M dos \& PEREIRA, R.M.F.A. Análise histórico-espacial do ...

A interpretação da realidade florianopolitana, aonde originalmente a atividade portuária (praça comercial) somada à função político- administrativa promoveu o desenvolvimento da atividade hoteleira, encontra suporte ainda nas reflexões de Milton Santos (1998) ao afirmar que "os elementos do espaço são determinados pelos homens, pelas firmas, pelas instituições, pelo suporte ecológico,e pelas infra-estruturas". Nas últimas décadas a atividade turística exerceu um papel preponderante expresso em todos os elementos da oferta e da demanda, num movimento de ação e interação recíprocas.

Assim sendo, e considerando a expansão urbana de Florianópolis, bem como o crescimento dos fluxos turísticos que acabaram por alavancar o desenvolvimento do setor hoteleiro, fezse necessário analisar a organização do seu espaço urbano central, buscando apreender as distintas funções desempenhadas pela cidade em diferentes épocas, resgatando o processo responsável pelas suas características atuais. Tal realidade pode ser apreendida através das categorias de forma, função, estrutura e processo, enquanto método que objetiva decompor e recompor a totalidade, interpretando o espaço geográfico, conforme sugere Milton Santos, na obra Espaço e Método.

\section{A formação litorânea catarinense}

Para melhor entender as transformações ocorridas na cidade de Florianópolis foi preciso, primeiramente, realizar uma análise espaço-temporal da formação litorânea brasileira e catarinense, em particular. O território que hoje corresponde ao Brasil foi povoado por iniciativa da Coroa Portuguesa, cuja ocupação se fez a partir do litoral, obedecendo a uma política expansionista, sobretudo no que concerne às terras localizadas na porção Meridional da colônia portuguesa, a fim de garantir a posse de grandes extensões do território disputado pelos dois reinos ibéricos: Portugal e Espanha.

A estratégia de povoamento do litoral sul teve como ponto de partida a capitania de São Vicente de onde se irradiou a formação de outros núcleos de povoamento. De acordo com 
SANTOS, F.M dos \& PEREIRA, R.M.F.A. Análise histórico-espacial do ...

historiadores catarinenses, no século XVII foram fundadas no litoral de Santa Catarina, as vilas de São Francisco do Sul, Nossa Senhora do Desterro (Florianópolis) e Santo Antônio dos Anjos da Laguna (Laguna), consideradas postos avançados dos portugueses no sentido Norte-Sul, que dependiam da via marítima e das condições portuárias para estabelecer contato com outros núcleos coloniais de povoamento situados na faixa costeira.

O litoral catarinense foi escolhido como principal alvo da política expansionista de Portugal na ocupação do território meridional brasileiro, utilizando-se para tanto dos recursos naturais disponíveis. A experiência colonizadora se associava, também, à estratégia de defesa territorial e ao uso diversificado da terra, principalmente, a de Nossa Senhora do Desterro que, como porta de entrada do Brasil Meridional, recebeu um número significativo de açorianos a partir do século XVIII, servindo de local de apoio para abastecimento de embarcações e como rota obrigatória para atingir a bacia do rio da Prata (MAMIGONIAN, 1998).

\section{O significado do porto no desenvolvimento da cidade}

Em 1738, com a criação da Capitania de Santa Catarina, Desterro torna-se a capital político-administrativa, tendo sua forma urbana inicial, sofrido intervenção de uma política de fortificação e de edificações executada pelo Brigadeiro José da Silva Paes. O espaço urbano de Desterro, que em 1894 passa a se chamar Florianópolis, estava, até o começo do século XX, limitado à área circunvizinha ao porto, expandindo-se posteriormente até o sopé das encostas dos morros situados nas proximidades (PELUSO JR., 1991). A cidade foi, pois, marcada originalmente pelas atividades portuárias e administrativas e, em conseqüência, o seu processo de urbanização foi, de início, ajustado às exigências destas funções destacando-se como uma importante praça comercial. Como ocorreu com outras cidades brasileiras, era estratégica a presença do porto para viabilizar a ligação por mar com outros portos da faixa litorânea e com a própria metrópole lusitana. As cidades portuárias assumiam um papel importante frente às políticas 
SANTOS, F.M dos \& PEREIRA, R.M.F.A. Análise histórico-espacial do ...

expansionistas dos colonizadores. Este foi, também, o caso da póvoa de Desterro, o porto foi um elemento importante na sua origem e evolução.

A cidade obteve lugar de destaque dada a sua posição geográfica privilegiada, localizada entre as duas principais cidades da costa atlântica: o Rio de Janeiro e Buenos Aires. Associada também à função portuária, destacaram-se, desde cedo, as funções comerciais e administrativas, que desempenharam importante papel na organização de serviços prestados à população local, bem como de estruturas criadas para atender aos viajantes. As relações comerciais estabelecidas com outras áreas possibilitaram o crescimento da produção e o aprimoramento técnico. Dentre os principais produtos comercializados destacavam-se o óleo de baleia e o pescado seco, além da farinha de mandioca, produtos que na época colonial eram exportados para o Norte e Nordeste do Brasil e também para a Europa.

A imigração européia em meados do século XIX deu grande impulso ao porto, que passou a centralizar, então, a maior parte da exportação dos produtos da região. A estrutura urbana pouco se alterou nesse período, embora a relações comerciais tenham se intensificado através do porto (PELUSO JR, 1991, p. 329).

A importância do porto estava relacionada ao seu papel de escoadouro da produção agrícola do litoral catarinense, despontando como principal produto de exportação da época a farinha de mandioca, distribuída também pelos portos de Laguna e São Francisco. Assim, no final do século XIX e início do século $\mathrm{XX}$, a cidade de Florianópolis assume posições importantes, como praça importadora de produtos provenientes de outras regiões do Brasil e da Europa, ocasião em que os comerciantes açorianos foram sendo substituídos por comerciantes de origem alemã, dentre os quais destacou-se Carl Hoepcke, responsável pela construção do estaleiro Arataca (1895), da Fábrica de Pontas Rita Maria (1896), da Fábrica de Gelo (1897) e da Fábrica de Rendas e Bordados (1913). As atividades do empresário Carl Hoepcke, considerado o pioneiro da industrialização em Florianópolis, contribuíram de 
SANTOS, F.M dos \& PEREIRA, R.M.F.A. Análise histórico-espacial do ...

maneira decisiva para o desenvolvimento comercial da cidade. Segundo aponta Bastos (2000), a atuação de outros comerciantes, tais como Wendhausen, Mayer, Born e Muller, também concorreram para a modernização do porto e a ampliação das relações mercantis com outros mercados, propiciando o comércio de uma grande variedade de artigos e fazendo com que o capital comercial florianopolitano fosse aos poucos se concentrando nas mãos destes descendentes de imigrantes europeus.

Vê-se, pois, que o porto foi um elemento fundamental nas origens e evolução da cidade. $\mathrm{O}$ interesse comercial representado pela possibilidade de transações com os navios que ancoravam na baía, fez da linha da praia a área de maior concentração da população. A ponte Hercílio Luz, inaugurada em 1926, também teve significado especial para a cidade abrindo uma nova era para a circulação de pessoas e mercadorias e favorecendo o crescimento da população. Logo após a sua inauguração surgiram diversas linhas de ônibus, que passaram a substituir as antigas travessias realizadas através do canal.

Até 1930, Florianópolis permanecia como o maior centro exportador e a maior cidade do Estado. A revolução de 30 assinala uma nova conjuntura marcada por grandes mudanças na estrutura sócio-econômica e política brasileira com a chegada ao poder das camadas sociais nacionalistas e a formação de um novo pacto político que une latifundiários, ligados ao mercado interno, e a burguesia industrial nascente, excluindo do poder os comerciantes de importação e exportação que constituíam a classe dominante local (PEREIRA, 2003, p.7). A função portuária indutora das atividades comerciais, entretanto, não resistiu a essa nova conjuntura econômica e social, entrando em decadência em meados do século XX. Com o fechamento do porto em 1970, se consolidou a condição de centro político-administrativo, onde passaram a predominar as atividades terciárias, que crescentemente imprimiram um novo dinamismo à cidade como prestadora de serviços atribuindo-lhe, pois, novas funções decorrentes de mudanças na estrutura sócio-econômica. 
A função portuária, contudo, foi decisiva para a formação de um centro urbano-exportador, devido às relações que se estabeleciam através do porto, desencadeando o crescimento populacional e o desenvolvimento de novas estruturas urbanas e de bens de serviço para os residentes locais, bem como para os visitantes da cidade.

\section{Expansão urbana e origens do setor hoteleiro}

Como conseqüência do incremento das viagens e do comércio, surgem os primeiros meios de hospedagem que se caracterizavam como estabelecimentos de passagem, para um único pernoite, já que as longas distâncias tornavam necessária a existência de locais para descanso. Inicialmente, os viajantes contavam somente com a hospitalidade dos habitantes da região, devido à inexistência de locais destinados ao acolhimento das pessoas que chegavam à cidade. De acordo com Pires (2001, p.127), os viajantes estrangeiros no século XIX surpreenderam-se com a hospitalidade brasileira que somada à generosidade e à afabilidade no trato, representam um traço do caráter brasileiro.

Durante as expedições pelo litoral brasileiro, em passagem pela Ilha de Santa Catarina, alguns destes viajantes estrangeiros ${ }^{1}$ descreveram o cotidiano, a paisagem e a hospitalidade dos moradores da época. Bougainville, expressa a hospitalidade recebida na casa do governador com jantar e baile; não bastasse, Lisle também confirma a mesma acolhida recebida no palácio, onde os quartos foram oferecidos durante uma estadia de três semanas. Destaca ainda, "fomos tratados com a maior cortesia por parte do governador e pelos principais habitantes da Ilha". Já outro viajante, Jean-François Galaup de La Pérouse (1785) descreve a

\footnotetext{
${ }^{1}$ Os relatos dos viajantes estrangeiros citados no texto foram identificados nas obras: HARO, A. P. Ilha de Santa Catarina: relato dos viajantes estrangeiros nos séculos XVIII e XIX. Florianópolis: UFSC, 1996; CABRAL, O. R. Nossa Senhora do Desterro. Florianópolis: UFSC, 1979; SAINT-HILARE, Auguste. Viagem à Curitiba e Província de Santa Catarina. São Paulo: Universidade, 1978.
} 
SANTOS, F.M dos \& PEREIRA, R.M.F.A. Análise histórico-espacial do ...

população como tendo "costumes delicados" e os habitantes como "polidos, serviçais, mas supersticiosos e ciumentos de suas mulheres". Cabral (1979, p.249) aponta que até 1811, não havia em Desterro hotéis e nem hospedarias, sendo o Palácio frequentemente utilizado para hospedagem e realização de bailes. $\mathrm{O}$ viajante René Primevère Lesson ${ }^{2}$, em 1822, afirma que Nossa Senhora do Desterro não oferecia aos estrangeiros nem hotel, nem restaurantes, nem café. Como em todas as colônias portuguesas encontravam-se várias tendas de revendedores, espécies de tabernas onde se dava de beber e comer, e onde a "ralé" e os negros, vinham se regalar com peixe seco e araque. Cabral (1979, p. 156) confirma a existência de tabernas freqüentadas por negros escravos, quando "um concessionário chamado José Monteiro foi advertido pela Câmara, por fazer da sua taberna alojamento para pernoitarem os escravos, destinados ao serviço da iluminação da cidade". As tabernas eram chamadas de "taberna de molhados", pois vendiam todo tipo de gêneros alimentícios.

Portanto, na Florianópolis da primeira metade do século XIX não havia estabelecimentos adequados para a acomodação dos viajantes que chegavam à Ilha de Santa Catarina. Tanto isso é verdade que os relatos acima comprovam que as personalidades ilustres eram recebidas no próprio Palácio. Quanto aos demais, restava a própria embarcação ou dependiam do acolhimento dos moradores locais.

É na região do porto e do Largo do Palácio, onde concentrava-se o comércio varejista, que surgem os primeiros estabelecimentos hoteleiros, a partir de meados do século XIX, identificados na obra do historiador Osvaldo Cabral (1979) e nos

\footnotetext{
${ }^{2}$ Lesson era naturalista, pertenceu à expedição comandada por Duperrey, a qual aportou em Santa Catarina em 1822, ano em que foi proclamada a Independência do Brasil. Permaneceu na Ilha por quatorze dias e fez um rico relato da flora e da fauna, bem como dos costumes locais (HARO, 1996).
} 
SANTOS, F.M dos \& PEREIRA, R.M.F.A. Análise histórico-espacial do ...

jornais de época ${ }^{3}$. Entre as primeiras iniciativas do período estão: o Hotel do Commercio (1850); o Hotel Brasil (1856); o Hotel Café (1856); o Hotel da Praça (1857); o Hotel do Vapor (1857); o Hotel Universo (1859); o Hotel dos Paquetes (1864); o Hotel Papini (1871); o Hotel Trajano (1876); o Grande Hotel (1884). Os hotéis do século XIX tinham características estruturais diferenciadas dos atuais. Alguns mantinham no piso térreo uma espécie de armazém onde também podia-se encontrar uma grande variedade de produtos alimentícios, produtos homeopáticos, bebidas, cigarros, café, velas de carnaúba, papel, além de outros objetos colocados a venda. Esses empreendimentos eram caracterizados como edificações com partido arquitetônico horizontal, onde funcionavam, no primeiro piso, um comércio de secos e molhados e, no segundo, dormitórios para hospedagem com banheiro coletivo. A maioria dos estabelecimentos fornecia refeição completa: café, almoço e jantar. O público freqüentador dessa hotelaria era dos mais variados, desde artistas, políticos até viajantes. Os serviços realizados pela hotelaria do século XIX atendiam também a eventos sociais, com destaque para o hotel do Vapor que era conhecido pela sua diversidade gastronômica e pelo jogo, tendo se tornado o principal ponto de encontro da sociedade da época.

Assim como a cidade, o setor hoteleiro no início do século $\mathrm{XX}$, apresentava os primeiros ares de modernidade, estimulado sobretudo pela construção da ponte Hercílio Luz, que deu maior fluidez ao transporte rodoviário, facilitando a chegada à Ilha de novos produtos e pessoas advindos de outros estados. Também no início do século XX (1932), inaugura-se o Hotel La Porta, com quatro andares, sendo o primeiro hotel com elevador de Santa Catarina. O proprietário, Sr. Ângelo M. La Porta, era concessionário e diretor da loteria de Santa Catarina e adquiriu o prédio onde estivera instalada a firma de André Wendhausen,

${ }^{3}$ Os jornais de época consultados no decorrer da pesquisa foram: Novo Íris 05/07/1850; Correio Catharinense - 02/11/1853; O Conservador 07/08/1855; O Conservador - 27/04/1855; 0 Conservador - 20/11/1855; O Despertador-17/05/1864; A Província - 08/11/1871; O Argos - 22/12/1859. 
SANTOS, F.M dos \& PEREIRA, R.M.F.A. Análise histórico-espacial do ...

fazendo as adaptações necessárias para comportar 180 apartamentos. O Hotel La Porta foi desativado e reestruturado para abrigar a agência Miramar da Caixa Econômica Federal. O prédio foi finalmente demolido em 1990, através do método de implosão, a primeira registrada em Florianópolis (VEIGA, 1993, p. 212).

Segundo Peluso Jr (1991, p. 318), a população de Florianópolis em 1900 era de 13.474 indivíduos e já atingira em 1940 os 25.014 habitantes, aumento populacional que exigiu um grande número de habitações. Em 1950, a cidade já com 48.264 habitantes, apresentando, então, um aspecto agradável, com praças e ruas arborizadas. Para proporcionar maior conforto urbano à população, infra-estruturas e serviços foram implantados, tais como serviços de telefone, água encanada, luz elétrica, esgoto sanitário, linhas de bonde e novas opções de moradia e de lazer (VEIGA, 1993, p. 149).

Nas décadas de 1950 e 1960, surgem as empresas estatais e órgãos ligados à administração pública, entre os quais as Centrais Elétricas de Santa Catarina - CELESC, o Banco de Desenvolvimento do Estado (BESC), a Companhia de Processamento de Dados do Estado de Santa Catarina (PRODASC), a Imprensa Oficial do Estado (IOESC) e a Universidade Federal de Santa Catarina (UFSC), as quais alavancaram o crescimento populacional da cidade, que já abrigava, 72.889 habitantes (PELUSO JR., 1991, p. 340). O crescimento urbano de Florianópolis se acelera a partir de então e com a construção da BR101, inaugurada em 1971, a comunicação e o acesso aos diversos pontos do território catarinense e destes com a capital é facilitada. A crescente classe média ganhou representatividade, loteando novos bairros residenciais. $\mathrm{O}$ poder público estadual e federal transforma o âmbito das atividades administrativas, com investimentos que reforçaram o setor terciário superior. Em 1970, deu-se a transferência da sede ELETROSUL (Centrais Elétricas do Sul do Brasil) do Rio de Janeiro para Florianópolis.

Os funcionários da ELETROSUL, recém chegados à Florianópolis, possuíam um poder aquisitivo elevado, o que provocou um aquecimento no mercado imobiliário em função da 
SANTOS, F.M dos \& PEREIRA, R.M.F.A. Análise histórico-espacial do ...

demanda por terrenos, casas e apartamentos. Essa expansão do mercado imobiliário, além de gerar transformações na organização do espaço urbano, impulsionou também o ramo da construção civil. Florianópolis passa a atrair um contingente maior de pessoas, estudantes, professores e empresários, estimulados pela criação e pela atuação de grandes empresas estatais estaduais e federais. Foi a partir desse período que ocorreram grandes transformações na configuração urbana da cidade, com o adensamento do núcleo central e a expansão de sua periferia, de forma tentacular. A construção da BR 101, a fundação da Universidade Federal de Santa Catarina e a vinda da ELETROSUL para Florianópolis, foram três fatos fundamentais no processo de urbanização da capital. As modificações ocorridas na cidade, diante do incremento do aparelho estatal, resultaram numa nova demanda por trabalhadores qualificados, que se refletiu num aumento populacional significativo em relação ao contingente de habitantes nativos. Formou-se, assim, um novo mercado consumidor que fomentou o desenvolvimento da construção civil e a das atividades turísticas a partir de 1970.

\section{A atividade turística e a evolução do setor hoteleiro}

As primeiras manifestações de entretenimento e lazer em Florianópolis, posteriormente associadas ao turismo vêm através do banho de mar, no início como uma atividade desportiva realizada próxima à área central e, posteriormente, com as segundas residências de florianopolitanos, construídas nas praias próximas do continente e, um pouco mais tarde, nos balneários situados na própria Ilha. Diante desta nova realidade, surgiram as primeiras infra-estruturas turísticas e teve início o processo de urbanização dessas áreas, consideradas privilegiadas pela elite local, e posteriormente apropriadas pelo turismo de massa. Até as décadas de 1950 e 1960, os moradores da área urbana central, freqüentavam as praias do continente: a praia do Balneário localizada no bairro do Estreito; as praias da Saudade, Bom Abrigo, Praia do Meio e Itaguaçu, localizadas no bairro de Coqueiros. Inicialmente estes espaços eram utilizados pelos habitantes locais para 
SANTOS, F.M dos \& PEREIRA, R.M.F.A. Análise histórico-espacial do ...

o lazer. Com o passar do tempo, urbanizaram-se e tornaram-se áreas de residências permanentes e impróprias para banho de mar. Até então, a rede hoteleira localizada na área central de Florianópolis ainda era bastante incipiente. Entre os anos de 1940 e 1960, a cidade possuía os seguintes estabelecimentos: Hotel Majestic $(1930)^{4}$, Hotel Metropol (1940), Hotel Central (1948) que, em 1965 passou a chamar-se Mário Hotel, Lux Hotel (1950), Hotel Querência (1958), Hotel Royal (1960) ${ }^{5}$, Oscar Hotel (1960), City Hotel (1968) e Hotel Cruzeiro (1968).

Os hóspedes, neste período, são pessoas cujas atividades estão direta ou indiretamente ligadas ao governo do estado de Santa Catarina, tais como políticos do interior e/ou executivos,

\footnotetext{
${ }^{4}$ O Hotel Majestic foi construído em concreto armado, por iniciativa do imigrante libanês José Daux, que chegara ao Brasil por volta de 1890. Em 1926, com acesso à Ilha facilitado pela construção da Ponte Hercílio Luz, percebeu a necessidade de um estabelecimento hoteleiro para hospedar os negociantes que cada vez mais visitavam a cidade. Em 1930, surgiu o primeiro Hotel Majestic, inaugurando a tradição da família Daux, no ramo hoteleiro de Florianópolis. Posteriormente outras famílias administraram o empreendimento, como as famílias Pessi (1950) e Cordiolli (1960). Hugo Pessi, foi por muito tempo o maior empresário do ramo da hotelaria da cidade, explorando simultaneamente os hotéis Metropol, Central e Majestic. A família Daux investiu fortemente em empreendimentos hoteleiros localizados no Balneário de Canasvieiras no Norte da Ilha de Santa Catarina. O último empreendimento inaugurado foi o Hotel Majestic, localizado na Av. Beira Mar Norte (SANTOS, 2005).

${ }^{5}$ Em 1958, o empresário de Florianópolis, Osmar Regueira, contando com recursos próprios obtidos através das Relojoarias Royal, Rio e Rossi, localizadas no centro da cidade, iniciou a construção do Hotel Royal, que manteve uma alta taxa de ocupação até a década de 1980. Em razão da degradação social no entorno, da construção do Terminal Urbano de Florianópolis, e do fechamento da rua Antônio Luz, bem como o bloqueio da rua João Pinto ao trânsito de veículos, em 1990 o estabelecimento deixou de ser competitivo, vindo a encerrar suas atividades no ramo da hotelaria em 2005. Assim como aconteceu com outros empreendimentos hoteleiros, seu prédio foi transformado em salas comerciais (SANTOS, 2005).
} 
SANTOS, F.M dos \& PEREIRA, R.M.F.A. Análise histórico-espacial do ...

engenheiros de empreiteiras, que vinham tratar de seus interesses na capital. A hotelaria também atendia em determinados períodos do ano, aos professores, estudantes e funcionários da Universidade Federal de Santa Catarina, além de representantes comerciais que vinham constantemente à cidade. Os hóspedes eram provenientes do interior do estado de Santa Catarina e dos estados vizinhos: Rio Grande do Sul e Paraná.

Até o início dos anos de 1970, devido à distância do núcleo central e também às deficiências do sistema viário, as áreas balneárias compostas por comunidades pesqueiras e rurais se mantiveram sem grandes alterações, prevalecendo as casas de veraneio, cujos proprietários pertenciam à elite florianopolitana. A cultura urbana do lazer e da busca por balneários, aliada à melhoria do acesso decorrente da construção da SC 401, promoveu o crescimento urbano das localidades situadas no Norte da Ilha e a intensificação do fluxo turístico.

A cidade apresenta considerável crescimento do índice de pessoas provenientes de outros estados e municípios de Santa Catarina, que migravam para a capital estimulados pela oferta de emprego, em atividades de serviços, comerciais e/ou públicas. Esse processo migratório, incentivado também pelo incremento estatal, resultou num crescimento populacional nas três últimas décadas, como se observa no quadro abaixo:

Quadro 1: Evolução da população de Florianópolis de 1970 a 2006

\begin{tabular}{|c|c|c|c|c|c|c|}
\hline Ano & $\mathbf{1 9 7 0}$ & $\mathbf{1 9 8 0}$ & $\mathbf{1 9 9 1}$ & $\mathbf{2 0 0 0}$ & $\mathbf{2 0 0 4}$ & $\mathbf{2 0 0 6}$ \\
\hline $\mathrm{N}^{\circ}$ de habitantes & 138.337 & 187.871 & 254.941 & 341.781 & $369.102^{*}$ & $406.564^{*}$ \\
\hline
\end{tabular}

* População estimada.

Fonte: IBGE, 2006.

O crescimento populacional é acompanhado, também, pela expansão dos fluxos turísticos, sendo que o aumento de pessoas provenientes de outras regiões de Santa Catarina, bem como de outros estados e até mesmo de países do extremo Sul, como Argentina, Paraguai e Uruguai, favoreceu a ampliação da oferta de 
SANTOS, F.M dos \& PEREIRA, R.M.F.A. Análise histórico-espacial do ...

equipamentos e serviços turísticos, tais como, meios de hospedagem, alimentação, agenciamento, transporte turístico, locação de veículos, entretenimentos e comércio turístico. Outro fato que teve um papel de destaque no incremento da atividade turística foi a inauguração do aeroporto Hercílio Luz, em 1976, e, posteriormente, a sua ampliação, em 1988, para receber aviões de grande porte ${ }^{6}$.

Os dados do quadro abaixo comprovam o crescimento numérico dos turistas que visitam Florianópolis no período da alta temporada (janeiro e fevereiro), conforme a pesquisa de demanda da SANTUR.

Quadro 2: Expansão do turismo em Florianópolis

\begin{tabular}{|c|c|c|c|c|c|c|}
\hline Ano & 1986 & 1990 & 1998 & 2000 & 2005 & 2007 \\
\hline $\begin{array}{c}\mathrm{N}^{\circ} \text { de turistas } \\
\text { Nacionais }\end{array}$ & 131.790 & 243.820 & 272.643 & 335.132 & 453.516 & 637.488 \\
\hline $\begin{array}{c}\mathrm{N}^{\circ} \text { de turistas } \\
\text { Estrangeiros }\end{array}$ & 67.710 & 58.837 & 85.815 & 171.109 & 120.582 & 143.095 \\
\hline Total & 199.500 & 302.657 & 358.458 & 506.241 & 574.098 & 780.583 \\
\hline
\end{tabular}

Fonte: SANTUR, $2007^{7}$

${ }^{6}$ A História do Aeroporto Internacional de Florianópolis - Hercílio Luz remonta aos primórdios da aviação na América do Sul. Em 1922, a Ilha de Santa Catarina foi escolhida para abrigar as instalações do Sistema de Defesa Aérea do litoral do Brasil. Neste período, começaram as obras no campo da Ressacada que abrigaria o Centro de Aviação Naval de Santa Catarina. $\mathrm{Na}$ época, o céu era de exclusividade dos hidroaviões em Florianópolis. Em 1927, o Centro de Aviação já dispunha de uma pista de pouso para aeronaves terrestres. O Ministério da Aeronáutica inaugurou, em 1955, o terminal de passageiros sob administração do Departamento de Aviação Civil. No período de 1974, a Infraero recebeu a jurisdição do Aeroporto de Florianópolis, tendo sido inaugurados o terminal de cargas e o novo terminal de passageiros (SANTOS, 2005).

${ }^{7}$ SANTUR - Órgão oficial de Turismo do Estado de Santa Catarina. Os dados da pesquisa de demanda citados são levantados pela SANTUR e referem-se apenas à realidade da alta temporada ( janeiro e fevereiro, período em que os fluxos turísticos se intensificam em todo Litoral Catarinense). 
SANTOS, F.M dos \& PEREIRA, R.M.F.A. Análise histórico-espacial do ...

A década de 1980 foi marcada pela expansão da atividade turística na Ilha de Santa Catarina, em conseqüência da presença de consumidores turísticos provenientes dos países vizinhos (Argentina, Paraguai e Uruguai), motivados pela atratividade paisagística local e também pelas vantagens monetárias decorrentes da política cambial da época. Nesse período, tem início a construção de uma rede hoteleira nos balneários do Norte da Ilha, ao mesmo tempo que se constata uma alteração da rede hoteleira situada no centro da cidade. É interessante observar que dentre os hotéis instalados no período de 1930 a 1959, permanecem em atividade atualmente apenas o Hotel Cruzeiro, localizado na Rua Conselheiro Mafra e o Hotel Sumaré, situado à Rua Felipe Schmidt. Outro registro importante quanto aos hotéis deste período, diz respeito a sua concentração numa área específica do centro da cidade. Já os hotéis inaugurados de 1960 a 1989 indicavam a tendência de verticalização, acompanhando o novo padrão arquitetônico das construções do centro da cidade e introduzindo melhorias físicas e de serviços, como dormitórios com banheiro privativo e serviços completos de hotelaria.

A figura 1 demonstra a evolução hoteleira no núcleo central de Florianópolis a partir da década de 1930.

A partir da década de 1990, registra-se uma nova conjuntura turística em Florianópolis, estimulada pelo turismo de negócios e eventos que minimizam a sazonalidade.

Em 1995 instala-se o primeiro hotel de rede internacional a operar na cidade com a marca Parthenon pertencente ao grupo Accor. Em 2006, houve uma mudança de bandeira, passando a funcionar com a marca Mercure, também do grupo Accor. Entretanto, foi a partir do ano 2000 que se deu a efetiva entrada das bandeiras de hotéis integrantes de redes hoteleiras nacionais e internacionais, tais como a rede Blue Tree (Blue Tree Towers), a rede InterCity (InterCity Premium) e a rede Accor (Mercure, Ibis, Sofitel), rede Deville com a administração do hotel Coral Plaza em 2007, conforme observa-se no quadro 3. 


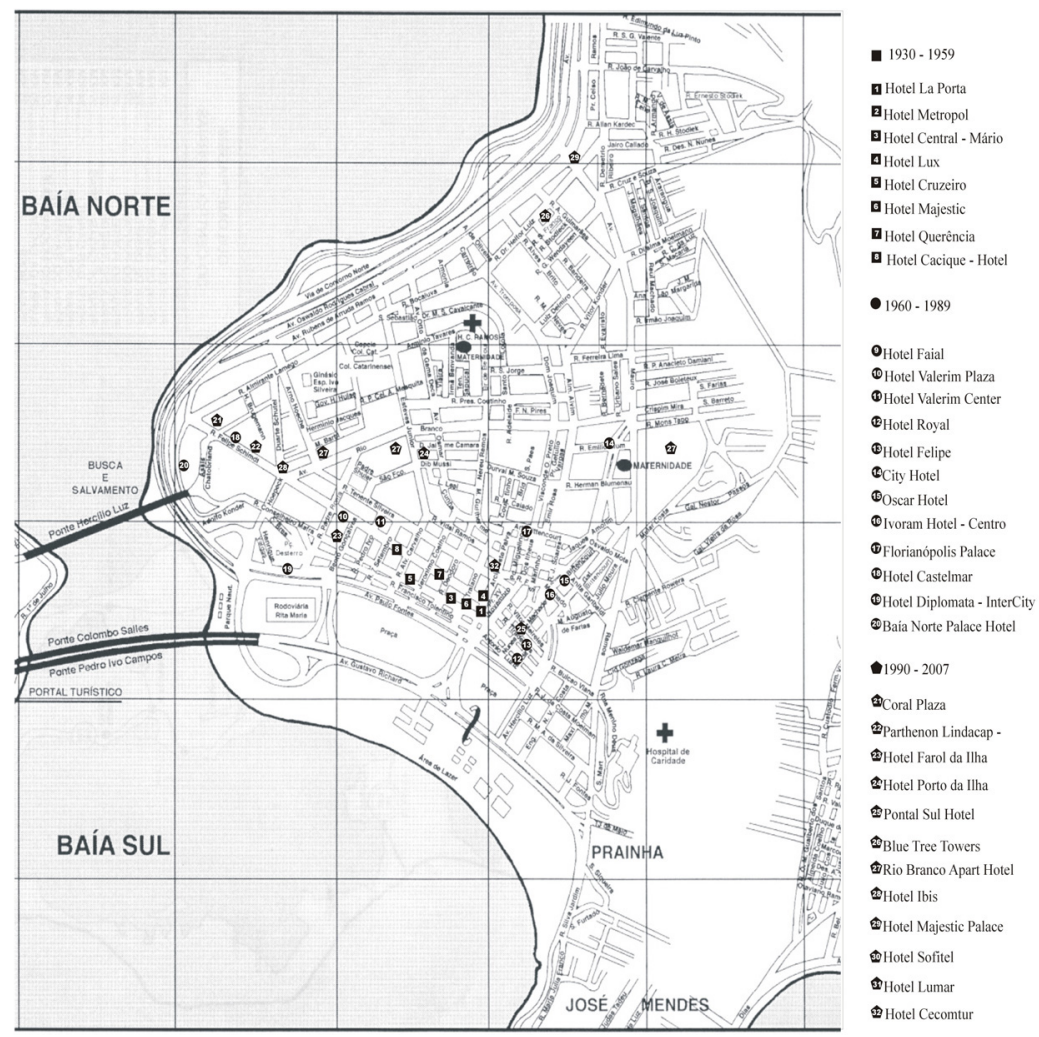

Figura 1: Mapeamento da Hotelaria localizada no núcleo urbano central de Florianópolis.

Fonte: Elaborado por Fabíola Martins dos Santos (2007). 
SANTOS, F.M dos \& PEREIRA, R.M.F.A. Análise histórico-espacial do ...

Quadro 3: Hotéis em funcionamento no núcleo central de Florianópolis

\begin{tabular}{|c|c|c|c|}
\hline Hotel & $\begin{array}{c}\text { Ano da } \\
\text { Inauguração }\end{array}$ & Proprietários atuais & Administração atual \\
\hline Oscar & 1960 & Nelson Cardoso & Independente \\
\hline Cruzeiro & 1968 & Arlinda Nienkötter & Independente \\
\hline City Hotel & 1968 & Gentil Cordiolli & Independente \\
\hline Centro Sul & 1972 & $\begin{array}{l}\text { CSH Hotelaria e Turismo Ltda } \\
\text { Cristiane Santos Piccoli }\end{array}$ & Independente \\
\hline Florianópolis Palace Hotel & 1975 & José de Oliveira & Rede Regional -Sagres \\
\hline Sumaré & 1975 & José Valerim & Independente \\
\hline Faial & 1979 & $\begin{array}{l}\text { Cleusa S. Silva } \\
\text { Roberta S. Silva } \\
\end{array}$ & Independente \\
\hline Castelmar & 1985 & $\begin{array}{l}\text { CHT Prestadora de Serviços S/C } \\
\text { Ltda } \\
\text { Renato Nunes Ghizoni } \\
\text { José Carlos Chaussard Neto }\end{array}$ & $\begin{array}{c}\text { Independente - } \\
\text { Participação na } \\
\text { administração: Rede } \\
\text { Bristol - Nacional } \\
\end{array}$ \\
\hline Baía Norte Palace Hotel & 1985 & Carmen Peters & Independente \\
\hline Valerim Plaza & 1985 & $\begin{array}{l}\text { José Valerim Junior } \\
\text { Soraya S. Valerim } \\
\text { Suzane S. Valerim }\end{array}$ & Independente \\
\hline Valerim Center & 1989 & $\begin{array}{l}\text { José Valerim Junior } \\
\text { Soraya S. Valerim } \\
\text { Suzane S. Valerim }\end{array}$ & Independente \\
\hline Rio Branco Apart Hotel & 1990 & Antônio César Chede & Independente \\
\hline Pontal Sul & 1992 & $\begin{array}{l}\text { Juliana M. de Sousa Santos } \\
\text { Gabriel Antunes de Sousa Santos }\end{array}$ & Independente \\
\hline Farol da Ilha & 1992 & $\begin{array}{l}\text { Cleusa S. Silva } \\
\text { Roberta S. Silva }\end{array}$ & Independente \\
\hline $\begin{array}{l}\text { Coral Plaza } \\
\text { Rede Devile (2007) }\end{array}$ & 1993 & $\begin{array}{l}\text { Montecarllo Empr. Turísticos } \\
\text { Aurelio Paladini } \\
\text { Mário Kenji }\end{array}$ & $\begin{array}{c}\text { Independente } \\
\text { Administradora Rede } \\
\text { Devile - Nacional (2007) }\end{array}$ \\
\hline $\begin{array}{l}\text { Parthenon Lindacap/ } \\
\text { Mercure (2006) }\end{array}$ & 1995 & $\begin{array}{l}\text { Condomínio com } 54 \\
\text { investidores }\end{array}$ & $\begin{array}{l}\text { Administradora - Rede } \\
\text { Accor - Internacional }\end{array}$ \\
\hline Porto da Ilha & 1998 & João Vicente Gomes & Independente \\
\hline Blue Tree Towers & 2000 & $\begin{array}{l}\text { Montecarllo Empr. Turísiticos } \\
\text { Mário Kenji } \\
\text { Aurélio Paladini }\end{array}$ & $\begin{array}{l}\text { Administradora - Rede } \\
\text { Blue Tree - Nacional }\end{array}$ \\
\hline Hotel Lumar & 2001 & Sálvio Sistarol & Independente \\
\hline Diplomata/Intercity & 2002 & Alexandre Gehlen & $\begin{array}{l}\text { Administradora: Rede } \\
\text { Intercity - Nacional }\end{array}$ \\
\hline Hotel Ibis & 2003 & $\begin{array}{l}\text { West Coral Hotéis e Resorts Ltda } \\
\text { Aurélio Paladini } \\
\text { Mário Kenji }\end{array}$ & $\begin{array}{l}\text { Administradora: Rede } \\
\text { Accor - Internacional }\end{array}$ \\
\hline Majestic Palace Hotel & 2004 & Ronaldo Daux & Independente \\
\hline $\begin{array}{l}\text { Cecomtur Executive } \\
\text { Hotel }\end{array}$ & 2005 & Crisciúma Construções Ltda & Independente \\
\hline Sofitel Florianópolis & 2006 & $\begin{array}{l}\text { Hbs Hotelaria Ltda } \\
\text { Aurélio Paladini } \\
\text { Anita Hoepke }\end{array}$ & $\begin{array}{l}\text { Administradora- Rede } \\
\text { Accor - Internacional }\end{array}$ \\
\hline
\end{tabular}

Fonte: Elaborado por Fabíola Martins dos Santos em 2005 e atualizado em 2007. 
SANTOS, F.M dos \& PEREIRA, R.M.F.A. Análise histórico-espacial do ...

\section{Considerações finais}

O presente texto aborda o processo de formação do núcleo central de Florianópolis e as suas transformações decorrentes do crescimento urbano e da expansão turística, bem como os seus reflexos no desenvolvimento da hotelaria na área central, particularmente nas últimas décadas.

O entendimento de que toda realidade concreta é fruto da combinação de elementos naturais e humanos responsáveis por uma totalidade que é construída espacial e temporalmente exigiu a análise do processo histórico responsável pela configuração do núcleo central de Florianópolis. Este enfoque permite perceber que as singularidades de um determinado local correspondem à conjugação de condicionantes naturais e humanos, endógenos e exógenos, ao longo de diferentes períodos históricos. No caso da cidade de Florianópolis, para estudar a sua configuração atual foi preciso conhecer a sua gênese e evolução, definindo os fatores que, ao longo do tempo, influenciaram a dinâmica da sociedade e seus reflexos materializados do espaço, já que as relações sociais dominantes se encarregam de moldar o traçado urbano da cidade e definir as suas principais funções em diferentes épocas.

Florianópolis teve seu destino marcado basicamente pelas funções portuária e administrativa e, em conseqüência, a organização de seu espaço ajustou-se às condições sócio-espaciais vigentes. Embora a função portuária tenha perdido gradativamente a sua importância, a função administrativa de capital e centro político do Estado de Santa Catarina se consolidou, favorecendo o predomínio das atividades terciárias e um crescente dinamismo na prestação de serviços. Os primeiros estabelecimentos hoteleiros de Florianópolis datam do século XIX e estavam localizados nas proximidades do porto e na região do Largo do Palácio. Possuíam características distintas das existentes hoje. As edificações que abrigavam os hotéis, além da hospedagem, acumulavam também a função de comércio varejista, disponibilizando vários produtos para o consumo da população local.

A atividade hoteleira no núcleo urbano de Florianópolis, representada por alguns estabelecimentos localizados na área central 
SANTOS, F.M dos \& PEREIRA, R.M.F.A. Análise histórico-espacial do ...

era ainda bastante incipiente até os anos de 1960 e 1970. Dentre os hotéis instalados nesse período, alguns não suportaram a competitividade de uma hotelaria mais moderna com inovações tecnológicas, deixando de funcionar como estabelecimentos de hospedagem, para investir em outros segmentos, exigindo a adaptação das edificações para incorporar novas funções. Alguns antigos hotéis transformaram suas instalações para a implantação de centros comerciais, como foi o caso do Lux Hotel, Hotel Querência e do Hotel Royal. Dos antigos hotéis somente o Hotel Cruzeiro e o Hotel Sumaré permanecem em atividade até os dias atuais. A partir de 1970, a instalação de órgãos estatais e a melhoria das infraestruturas urbanas, bem como os investimentos privados na atividade hoteleira e na prestação de serviços promovem a expansão urbana e do turismo. Embora até 1990 o turismo em Florianópolis tenha sido canalizado para as praias, o mercado turístico da região passou a sofrer grandes alterações a partir de 1998, com a intensificação dos fluxos turísticos de negócios e eventos que promovem modificações significativas na hotelaria localizada no núcleo central de Florianópolis, expressas, sobretudo, pela entrada das redes hoteleiras nacionais e internacionais no mercado local. Dessa forma, o setor hoteleiro modifica-se respondendo as transformações da própria cidade, pois, conforme ensina Milton Santos (1986, p.38), "os movimentos da totalidade social, modificando as relações entre componentes da sociedade, alteram os processos, incitam a novas funções. Do mesmo modo, as formas geográficas se alteram ou mudam de valor; o espaço se modifica para atender às transformações da sociedade".

\section{Referências bibliográficas}

BASTOS, J. M. Urbanização, comércio e pequena produção mercantil pesqueira na Ilha de Santa Catarina. In LINS Hoyedo; MESSIAS, José; CHEREM, Rosângela; SANTOS, Maurício. (Orgs). Ensaios sobre a Ilha de Santa Catarina. Florianópolis: Letras Contemporâneas, 2000. 
SANTOS, F.M dos \& PEREIRA, R.M.F.A. Análise histórico-espacial do ...

CABRAL, O. R. Nossa Senhora do Desterro. Florianópolis: UFSC, 1979.

HARO, A. P. Ilha de Santa Catarina: relato dos viajantes estrangeiros nos séculos XVIII e XIX. Florianópolis: UFSC, 1996.

INSTITUTO BRASILEIRO DE GEOGRAFIA E ESTATÍSTICA. Disponível em: www.ibge.gov.br. Acesso em 2007.

PELUSO Jr. Victor. Estudos de Geografia Urbana de Santa Catarina. Florianópolis: UFSC, 1991.

PEREIRA, R. M.F. Formação sócio-espacial do litoral de Santa Catarina (Brasil): gênese e transformações recentes. Florianópolis: Revista GEOSUL, 2003.

PIRES, M. J. Raízes do turismo no Brasil. São Paulo: Manole, 2001.

SAINT-HILAIRE, Auguste. Viagem à Curitiba e Província de Santa Catarina. São Paulo: Universidade, 1978.

SANTUR - Santa Catarina Turismo S/ A Pesquisa Mercadológica de Estudo da Demanda Turística de Santa Catarina. Disponível em: <http: www.sc.gov.br>. Acesso em: jul-nov. 2007.

SANTOS, M. Espaço e Método. São Paulo: Nobel, 1998.

SANTOS, Fabíola M. Uma análise histórico-espacial do setor hoteleiro no núcleo urbano central de Florianópolis. Dissertação de Mestrado do Programa de Pós-graduação em Turismo e Hotelaria da UNIVALI, 2005.

VEIGA, E. Florianópolis: memória urbana. Florianópolis:

Recebido em outubro de 2007 Aceito em junho de 2008 
